\title{
Glycated haemoglobin variations in paediatric type 1 diabetes: the impact of season, gender and age
}

\author{
Lena Hanberger, K. Akesson and Ulf Samuelsson
}

\section{Linköping University Post Print}

\section{Tweet}

N.B.: When citing this work, cite the original article.

Original Publication:

Lena Hanberger, K. Akesson and Ulf Samuelsson, Glycated haemoglobin variations in paediatric type 1 diabetes: the impact of season, gender and age, 2014, Acta Paediatrica, (103), 4, 398-403.

http://dx.doi.org/10.1111/apa.12530

Copyright: Wiley

http://eu.wiley.com/WileyCDA/

Postprint available at: Linköping University Electronic Press

http://urn.kb.se/resolve?urn=urn:nbn:se:liu:diva-106120 
Glycated haemoglobin variations in paediatric type 1 diabetes: the impact of season, gender and age

L Hanberger ${ }^{1} \mathrm{PhD}, \mathrm{RN}$

$\mathrm{K}$ Åkesson ${ }^{2,3} \mathrm{PhD}, \mathrm{MD}$

U Samuelsson ${ }^{1} \mathrm{PhD}$, Associate Professor, MD

${ }^{1}$ Division of Pediatrics, Department of Clinical and Experimental Medicine, Linköping University, Linköping, Sweden.

${ }^{2}$ Pediatric clinic, County Hospital Ryhov, Jönköping, Sweden

${ }^{3}$ Jönköping County Council and Jönköping Academy for improvement of health and welfare, Jönköping University

Short title: HbA1c variations in type 1 diabetes

Corresponding author:

L. Hanberger

Division of Pediatrics

Department of Clinical and Experimental Medicine

Faculty of Health Science, Linköping University

58185 Linköping

Sweden

Phone +46 10103 1378, +709962609

Fax +46 13148265

e-mail: lena.hanberger@lio.se 


\begin{abstract}
Aim: To study whether monthly variations in type 1 diabetes incidence are related to monthly glycated haemoglobin ( $\mathrm{HbA1c}$ ) levels at diagnosis and if high $\mathrm{HbA1c}$ at diagnosis is related to certain clinical variables at diagnosis and during the clinical course of the disease.
\end{abstract}

Methods: Data from 4,430 boys and 3,590 girls registered in the Swedish pediatric diabetes quality registry, SWEDIABKIDS, from 2000 to 2010 were analysed.

Results: Month of onset varied ( $p<0.001$ ), with $53 \%$ diagnosed during September to February, and mean $\mathrm{HbA1c}$ at diagnosis was highest in May $(10.9 \%, 96 \mathrm{mmol} / \mathrm{mol})$ and lowest in (October 9.4\%, $88 \mathrm{mmol} / \mathrm{mol})(\mathrm{p}<0.001)$. Girls showed higher $\mathrm{HbA} 1 \mathrm{c}$ at onset than boys $(p<0.001)$. More than half $(53 \%)$ with an annual mean $\mathrm{HbA} 1 \mathrm{c}$ of $>9.3 \%(78 \mathrm{mmol} / \mathrm{mol})$ and $4 \%$ of those with an annual mean of $<7.4 \%(57 \mathrm{mmol} / \mathrm{mol})$ in 2007 , had $>9.3 \%(78$ $\mathrm{mmol} / \mathrm{mol}$ ) in 2010 .

Conclusion: Patients with high $\mathrm{HbA1c}$ levels during a certain period have the same high levels several years later. This group, perhaps including those with high $\mathrm{HbA} 1 \mathrm{c}$ level at diagnosis, may need more intensive care, including extra support from the diabetes teams and other forms of medical treatment.

\title{
Key Notes:
}

- Data from 8,020 children were analysed to identify associations between variations in type 1 diabetes and glycated haemoglobin ( $\mathrm{HbA1c})$ in Sweden.

- Girls had higher levels at diagnosis and follow up and many children with poor metabolic control still had high $\mathrm{HbA} 1 \mathrm{c}$ several years later.

- A variation in month of onset was found, with $53 \%$ diagnosed during autumn and winter, but no seasonal variations in $\mathrm{HbA1c}$ were found during follow up.

\section{Key words}

HbA1c, type 1 diabetes, metabolic control, quality register, seasonal variations 


\section{Introduction}

Seasonal variations in glycated haemoglobin $(\mathrm{HbA1c})$ at follow-up have been observed in adults and children with type 1 diabetes, with the lowest values during the summer and the highest levels during the winter (1-5). Some studies have found the greatest seasonal variations in older age groups (4), but no gender differences have been reported. It has been suggested that these variations may be due to increased physical activity and fewer viral infections in the summer months and a colder climate during late autumn and winter $(4,5)$. It is not just $\mathrm{HbA1c}$ that is subject to seasonal variations. Many other systems in the body vary with the seasons, such as plasma cortisol and blood pressure, which are both higher during the winter $(6,7)$.

Seasonal patterns of onset of type 1 diabetes have been found, with incidence peaking in the winter months $(1-3,5)$ and in both sexes during puberty $(3)$. In contrast, other studies have found no seasonal differences in the month of onset in girls (8). Older children, however, show the greatest seasonal variations (5). The authors believed that these variations were due to children with less aggressive disease processes at diagnosis.

A geographical variability has also been found. The incidence data on children aged from 0 to 13 years, collected by the World Health Organization DiaMond study, showed that seasonal patterns depend on geographical position (9). Centres further from the equator are more likely to exhibit significant seasonal variations, although most of the data in the study came from the northern hemisphere. These seasonal patterns were also more frequent in older age groups. These findings are supported by reports of the inverse and independent relationships between incidence rates and mean sunshine hours and mean temperature (10). A correlation has been shown between $\mathrm{Hb1Ac}$ during the first years after diagnosis and later metabolic control (11).

Gender differences have also been found. Girls aged between six and 12-years-of-age years of age were found to have higher $\mathrm{HbA} 1 \mathrm{c}$ levels at diagnosis than boys of the same age and 
girls of other age groups (12). Moreover, poorer metabolic control has been found in girls than boys during the clinical course, especially during adolescence (13-15).

The Diabetes Control and Complications Trial study, and others, $(16,17)$ have shown that improved metabolic control is important to prevent, delay or slow the progression of longterm complications.

It is necessary to increase our knowledge of the factors that positively and negatively affect the risk of late complications. Quality registries enable us to do this and, in the Nordic countries, these include data from large populations. Using descriptive data enables us to study the relationships between specific factors and identify those patients who risk developing late complications.

Although previous research studies have demonstrated seasonal variability in metabolic control at follow-up, little is known about seasonal variations of $\mathrm{HbA} 1 \mathrm{c}$ at diagnosis. Therefore, the aim of this study was to investigate, in a large selected population, whether there are seasonal variations in HbA1c-values at diagnosis of type 1 diabetes and if this variation remains during the clinical course of the disease. Furthermore, we aimed to establish whether the monthly variation of diabetes incidence was related to the monthly mean levels of $\mathrm{HbA} 1 \mathrm{c}$ at diagnosis. 


\section{Patients and methods}

The Swedish pediatric diabetes quality registry

The Swedish pediatric diabetes quality registry (SWEDIABKIDS) was established in 2000 and includes outpatient attendance data from all 43 Swedish paediatric diabetes centres (18). In Sweden, paediatric clinics treat all children and adolescents with diabetes aged from 0 to 18 years from defined geographical areas. As a result, the registry includes data on around $99 \%$ of the children and adolescents with diabetes in Sweden. In 2010, It included data from more than 235,000 outpatient visits, but it does not provide data on socioeconomic factors.

Initially, data from 2000 to 2007 were registered locally in a specially designed childhood diabetes programme. But since 2008 , the registry has been web-based and is available to all paediatric diabetes centres in Sweden. SWEDIABKIDS is financially supported by the Association of Local Authorities and Regions, which represents the governmental, professional and employer-related interests of Sweden's municipalities, county councils and regions (19). It has national quality registry status and patients and parents are informed about the registry before agreeing to be included.

All methods used in Sweden are standardised through the External Quality Assurance in Laboratory Medicine in Sweden, EQUALIS. The data on HbA1c obtained from SWEDIABKIDS were derived from capillary blood samples measured with the Bayer/Siemens DCA-2000 analyser or with local laboratory methods. The IFCC (International Federation of Clinical Chemistry and Laboratory Medicine) reference method has been adopted in Sweden (20). For example, $58 \mathrm{mmol} / \mathrm{mol}$ (IFFC) corresponds to $7.5 \%$ NGSP/DCCT (National Glycohemoglobin Standardization Program /Diabetes Control and Complications Trial) and $10 \mathrm{mmol} / \mathrm{mol}$ is about $0.9 \%$. In this paper, $\mathrm{HbA1c}$ values will be presented as NGSP/DCCT (\%), followed by IFCC units $(\mathrm{mmol} / \mathrm{mol})$ in parenthesis, except for in tables and figures, where IFCC units are reported.

\section{Material}


According to the Swedish guidelines, children with diabetes visit the diabetes centre at least four times a year up to the age of 18 (21). At these visits, $\mathrm{HbA1c}$ and other clinical parameters, such as insulin dose, weight, length and blood pressure, are measured. Our study analysed data from 4,430 boys and 3,590 girls, aged 0 to 18 years of age, with type 1 diabetes, who were registered in SWEDIABKIDS between 2000 and 2010. We looked at month of onset $(n=8,020), H b A 1 c$ values at onset $(n=, 7539), p H(n=7,465)$, Body Mass Index standard deviation score $(n=3532)$, and blood pressure $(n=2,199)$. The patients were divided into four groups, based on their age at diagnosis: 0 to four years $(n=1,264)$, five to nine years $(n=2,493), 10$ to 14 years $(n=3,055)$ and $15-18$ years $(n=1208)$. The incidence of type 1 diabetes in 2008, 2009 and 2010 were 42, 45 and 42 per 100,000 per year, respectively (18).

To study the seasonality of $\mathrm{HbA} 1 \mathrm{c}$ during clinical follow-up, $\mathrm{HbA1c}$ values during 2008 to $2010(n=76,933)$ were analysed. To study the clinical course of HbA1c, data from 2007, the year all paediatric clinics in Sweden were included in the registry, were analysed on children and adolescents from one to 15-years-of-age. We also analysed data from 2010 on children and adolescents from three to 18-years-of-age, with mean year values from 4,935 patients. This was done using the clinical care cut points for $\mathrm{HbA} 1 \mathrm{c}$ laid down in the guidelines from the International Diabetes Federation/ International Society for Pediatric and Adolescent Diabetes (22): $<7.5 \%$ (58 mmol $/ \mathrm{mol})$ (target value, optimal control), $7.5-9.2 \%(58-77$ $\mathrm{mmol} / \mathrm{mol}$ ) (suboptimal control, actions suggested) and $>9.2 \%(78 \mathrm{mmol} / \mathrm{mol})$ (high risk, action required). Standard deviation score values based on age-standardised values were used to compared blood pressure.

\section{Statistical methods}

SPSS $18^{\circledR}$ (SPSS inc., Chicago, IL, USA) was used for the analyses. Student's t-test and one-way analysis of variance (Anova) was used. Chi-square was used for comparison of the monthly variation. The results are expressed as mean $\pm S D$. 


\section{Results}

Monthly variation

A variation was found regarding month of onset, with the fewest children diagnosed in May and June $(p<0.001)$ (Figure 1). Fifty-three percent of the patients were diagnosed during autumn and winter, from September to February, and $47 \%$ were diagnosed during spring and summer $(p<0.001)$. The monthly variation was somewhat more obvious for boys than for girls (Figure 1). This variation was seen in all age groups, but was most obvious in the youngest age group, with $42 \%$ diagnosed during spring and summer and $58 \%$ during autumn and winter $(p<0.001)$.

$\mathrm{HbA} 1 \mathrm{c}$ was the only clinical parameter analysed at onset that showed an obvious monthly variation. The mean $\mathrm{HbA} 1 \mathrm{c}$ value at onset for all children was $10.6 \%, \pm 2.3(92 \mathrm{mmol} / \mathrm{mol}$ $\pm 25.4)$. The mean value was highest in May at $11 \% \pm 2.2(97 \pm 25 \mathrm{mmol} / \mathrm{mol})$ and lowest in October at $10.3 \% \pm 2.4(87 \mathrm{mmol} / \mathrm{mol}, \pm 27)(p<0.001)$, as seen in Figure 1. This pattern was found in both boys and girls. The monthly variation was seen in the age groups 0 to four years, 10 to 14 years and $>14$ years $(p<0.01$, respectively). HbA1c during follow-up in 2008 to 2010 ( $n=75,069$ measurements,) showed no obvious monthly variations, with the highest mean value in December of $8.2 \% \pm 1.4(66 \pm 15 \mathrm{mmol} / \mathrm{mol})$ and the lowest in September of $8.1 \% \pm 1.4(65 \pm 15 \mathrm{mmol} / \mathrm{mol}$ ) (Figure 1). This pattern was seen in both genders, and in all age groups, as with $\mathrm{HbA1c}$ at onset

\section{From onset to follow up}

The HbA1c value at onset was higher in girls than in boys $(p<0.001)$ and this pattern was seen in three of the four age groups (Table 1). The $\mathrm{pH}$ value and the Body Mass Index standard deviations scores (SDS) at onset did not differ between the age groups. But at onset, the children in the youngest group had higher blood pressure than the children in the two oldest age groups, when it came to both systolic (0.62 SDS compared to 0.24 SDS and 0.24 SDS, respectively, $p<0.001)$ and diastolic blood pressure $(0.90$ SDS compared to 0.21 
SDS and 0.05 , respectively, $p<0.001)$. The differences were more obvious in girls than in boys. However, girls in the youngest age group had a body mass index SDS at onset of -0.61 compared with a body mass index SDS of $-0.38(p=0.1)$ in the oldest age group. This trend was not seen in the boys. Girls had higher $\mathrm{HbA1c}$ than boys during follow up. This pattern was found each year and was most obvious in the oldest age group, exemplified by the values in 2010 (Table 2).

Figure 2 shows that 1,866 children had an annual mean $\mathrm{HbA1c}$ value below the national target value of $7.4 \%(57 \mathrm{mmol} / \mathrm{mol})$ in 2007 and that $41 \%$ of those children still had this annual mean value in 2010 (Figure 2). Only 4\% of the children had an annual mean value of more than $9.3 \%$ (78 $\mathrm{mmol} / \mathrm{mol})$ in 2010 , whereas $55 \%$ of the children had increased their annual mean value to between 7.4 and $9.3 \%$. Of the 449 children with an annual mean value above $9.3 \%$ in $2007,53 \%$ still had the same high annual mean value in 2010 and only $6 \%$ of these children had decreased their annual mean value to less than $7.4 \%$ (Figure 2). Of the 2,620 children with a mean $\mathrm{HbA} 1 \mathrm{c}$ value between 7.4 and $9.3 \%, 74 \%$ had the same value in $2010,12 \%$ had a mean value of less than $7.4 \%$ and $14 \%$ had increased their value to above $9.3 \%$. As we have stated the $\mathrm{mmol} / \mathrm{mol}$ values for $7.4 \%$ and $9.3 \%$ early in this paragraph, I have taken out the subsequent references. 


\section{Discussion}

Most of the earlier studies addressed the seasonal variation in $\mathrm{HbA} 1 \mathrm{c}$ during the clinical course and found the highest values during the winter months $(5,23)$. We studied $\mathrm{HbA1C}$ values at diagnosis and found that the values were highest during the summer. A long duration of symptoms results in a higher $\mathrm{HbA1c}$ than a short duration and children diagnosed during the summer might have a longer duration of symptoms than children diagnosed in winter. The Swedish registry contains no information about the duration of symptoms. Young children under the age of five generally have a short duration. As this sub-group of children also showed this seasonal pattern, with high $\mathrm{HbA} 1 \mathrm{c}$ levels during the summer, it implies that other explanations than long duration are required. It is also unlikely that children diagnosed in the summer have more infections than children diagnosed during the autumn and winter. The only clinical variable that differed between the children who were diagnosed in May, compared to those diagnosed in October, at onset and during follow up, was the age at diagnosis. According to the present study, the month of diagnosis does not seem to affect the course of the disease.

Despite the fact that the present study contained a large amount of HbA1c measurements, a lot more than in most paediatric studies $(4,23)$, we could not confirm the seasonal variations during follow up that were found in other studies $(4,23)$. Children and adolescents with type 1 diabetes in Sweden are intensively treated with multiple insulin injections or insulin pump therapy and active self-control. Their glycaemic control is better than, or comparable to, other populations $(13,24,25)$. Perhaps this intense treatment can help these patients to handle the stress of the colder Swedish climate, and more infections during the winter, and equalise the $\mathrm{HbA1c}$ values over the year.

The results of this study indicate a gender difference, as girls generally had higher $\mathrm{HbA1c}$ than boys at diagnosis and during follow up. During the three-year follow up, this was only seen in children of more than 10-years-of-age, which might be explained by hormonal factors. In general, puberty starts one to two years earlier in girls than in boys. The gender difference was also seen in the youngest age group at diagnosis, but is not likely to be due to 
hormonal factors and could be explained by the fact that girls may be more metabolically unbalanced than boys at the time of diagnosis. It might be, however, that we are less likely to observe symptoms in girls than in boys. Unfortunately the duration of symptoms at diagnosis is not reported to the registry.

Another main finding of this study was that many of the children with poor metabolic control during a certain period still had high levels of $\mathrm{HbA} 1 \mathrm{c}$ several years later. This is discouraging, because the Diabetes Control and Complications Trial study, and other intervention studies, have convincingly shown that good glycaemic control is very important in order to avoid longterm complications $(16,17)$. The children with high $\mathrm{HbA} 1 \mathrm{c}$ values in this study were considered to have poor metabolic/glycaemic control as glycated haemoglobin is the standard index of glycaemic control over the preceding period of eight to 12 weeks (26). Several studies have also shown good correlation between $\mathrm{HbA} 1 \mathrm{c}$ and blood glucose levels over time $(26,27)$.

Although there is a correlations between high $\mathrm{HbA1c}$ during follow up and older age (12), the risk of retinopathy and albuminuria also increases in young patients with persistently poor metabolic control (28). Long duration of diabetes is another factor that increases the risk of long-term complications $(28,29)$, but duration of disease was not included in the present analysis. The children who had poor glycaemic control in both 2007 and 2010 must be considered to be at high risk of developing long-term complications early in adulthood. In contrast, there seemed to be a group of children - those with $\mathrm{HbA} 1 \mathrm{c}$ of $7.4 \%(57 \mathrm{mmol} / \mathrm{mol})$ in both 2007 and 2010 - who had a low risk of developing long-term complications. There is, however, no guarantee of this, as complications can occur despite good control (30). Almost $5 \%(n=4,935)$ of the patients with $\mathrm{HbA1c}$ values from both 2007 and 2010 must be considered at a very high risk of complications, whereas almost $16 \%(n=766)$ can be considered very low risk. It might be speculated that there is a group of children with a less aggressive form of type 1 diabetes, and thereby a low risk of complications, and another group with a more aggressive form that is harder to treat, with a high risk of complications and early death. This second group of patients, who perhaps include those with high $\mathrm{HbA1c}$ 
levels at diagnosis, may need more intensive care, including extra support from the diabetes teams and other forms of medical treatment.

The strength of the study is the large unselected population, which may increase its precision. The observation period was long and the children were followed prospectively. At least $99 \%$ of the patients diagnosed in Sweden each year are registered in SWEDIABKIDS and were included in this study. The registry provides $\mathrm{HbA1c}$ values for the vast majority of patients, but there is a lack of data regarding other variables such as body mass index and blood pressure. The centres that report the highest and lowest levels of complete data are randomly distributed from a geographic point of view. There are differences in annual mean $\mathrm{HbA1c}$ values between the clinics in Sweden and these are not explained by clinical variables (13). The latest annual report from the registry, based on data from 2011, shows a difference of $1.3 \%(14.2 \mathrm{mmol} / \mathrm{mol})(18)$. This can, of course, only influence follow-up data but not data regarding diagnosis. As the sample size of the measured follow-up data is very large, we believe that the differences between the clinics only marginally influence the results. Another factor that may influence the results is the fact that Sweden is a rather long and narrow country, with dark and cold winters and long daylight hours in the summer, especially in the north. The registry cannot, however, show any clear differences in HbA1c levels between southern and northern paediatric centres. As the seasonal variations in our study follow the same pattern shown in earlier studies from Sweden and other countries, of low incidence during the summer $(2,5)$, we believe that our results are robust. In summary, the seasonal variation in the incidence of diabetes and $\mathrm{HbA1c}$ values at diagnosis indicates an effect of environmental factors, but could also reflect an endocrine seasonality. Practitioners and researchers should be aware of seasonal variations and pay attention to its potential effects. The gender difference in $\mathrm{HbA1c}$ levels that is already present at onset could be due to physiological gender differences or that we are less aware of symptoms in girls. Many of the children with high $\mathrm{HbA} 1 \mathrm{c}$ levels during a certain period still had high levels several years later. This is an important finding for clinicians, as it indicates 
that this group of children, in particular girls, seem to require new ways of treatment and support.

\section{Acknowledgements}

We would like to thank other members of the SWEDIABKIDS steering committee, Bengt Lindblad, Auste Pundziute-Lyckå, Eva Örtqvist, Svante Norgren and Anna Olivecrona, and statistician John Carstensen for his advice.

This study was supported by the Östergötland County Council and Futurum, the academy for healthcare, Jönköping County Council.

\section{Conflict of interest}

The authors declare that there is no conflict of interest associated with this paper.

\section{Contribution statement}

All authors contributed to the design of the study. US prepared the database and performed the analyses. LH had the main responsible for writing the manuscript. KÅ and US contributed to interpretation the findings, writing and revising the manuscript, and agreed the final version to be published. 


\section{References}

1. Dahlquist G, Blom L, Holmgren G, Hagglof B, Larsson Y, Sterky G, et al. The epidemiology of diabetes in Swedish children 0-14 years--a six-year prospective study. Diabetologia. 1985; 28:802-8

2. Kalliora MI, Vazeou A, Delis D, Bozas E, Thymelli I, Bartsocas CS. Seasonal variation of type 1 diabetes mellitus diagnosis in Greek children. Hormones (Athens). 2011; 10:67-71

3. Levy-Marchal C, Patterson C, Green A. Variation by age group and seasonality at diagnosis of childhood IDDM in Europe. The EURODIAB ACE Study Group. Diabetologia. $1995 ; 38: 823-30$

4. Mianowska B, Fendler W, Szadkowska A, Baranowska A, Grzelak-Agaciak E, Sadon $\mathrm{J}$, et al. $\mathrm{HbA}(1 \mathrm{c})$ levels in schoolchildren with type 1 diabetes are seasonally variable and dependent on weather conditions. Diabetologia. 2011; 54:749-56

5. Samuelsson U, Carstensen J, Lofman O, Nordfeldt S. Seasonal variation in the diagnosis of type 1 diabetes in south-east Sweden. Diabetes Res Clin Pract. 2007; 76:75-81 6. Brennan PJ, Greenberg G, Miall WE, Thompson SG. Seasonal variation in arterial blood pressure. Br Med J (Clin Res Ed). 1982; 285:919-23

7. Walker BR, Best R, Noon JP, Watt GC, Webb DJ. Seasonal variation in glucocorticoid activity in healthy men. J Clin Endocrinol Metab. 1997; 82:4015-9

8. Roche EF, Lewy H, Hoey HM, Laron Z. Differences between males and females in the seasonality of birth and month of clinical onset of disease in children with type 1 diabetes mellitus in Ireland. J Pediatr Endocrinol Metab. 2003; 16:779-82

9. Moltchanova EV, Schreier N, Lammi N, Karvonen M. Seasonal variation of diagnosis of Type 1 diabetes mellitus in children worldwide. Diabet Med. 2009; 26:673-8 10. Dahlquist G, Mustonen L. Childhood onset diabetes--time trends and climatological factors. Int J Epidemiol. 1994; 23:1234-41 
11.

Chemtob CM, Hochhauser CJ, Shemesh E, Schmeidler J, Rapaport R. Does

poor early metabolic control predict subsequent poor control in young children with type 1 diabetes: an exploratory study. J Diabetes. 2011; 3:153-7

12. Hochhauser CJ, Rapaport R, Shemesh E, Schmeidler J, Chemtob CM. Age at diagnosis, gender, and metabolic control in children with type 1 diabetes. Pediatr Diabetes. 2008; 9:303-7

13. Hanberger L, Samuelsson U, Lindblad B, Ludvigsson J. A1C in children and adolescents with diabetes in relation to certain clinical parameters: the Swedish Childhood Diabetes Registry SWEDIABKIDS. Diabetes Care. 2008; 31:927-9

14. Setoodeh A, Mostafavi F, Hedayat T. Glycemic Control in Iranian Children with Type 1 Diabetes Mellitus: Effect of Gender. Indian J Pediatr. 2011;

15. Springer D, Dziura J, Tamborlane WV, Steffen AT, Ahern JH, Vincent M, et al. Optimal control of type 1 diabetes mellitus in youth receiving intensive treatment. $J$ Pediatr. $2006 ; 149: 227-32$

16. The effect of intensive treatment of diabetes on the development and progression of long-term complications in insulin-dependent diabetes mellitus. The Diabetes Control and Complications Trial Research Group. N Engl J Med. 1993; 329:977-86 17. Svensson M, Eriksson JW, Dahlquist G. Early glycemic control, age at onset, and development of microvascular complications in childhood-onset type 1 diabetes: a population-based study in northern Sweden. Diabetes Care. 2004; 27:955-62

18. The Swedish pediatric diabetes quality registry, SWEDIABKIDS. 2008. https://www.swediabkids.se (Accessed July 3, 2013) 19. The Swedish Association of Local Authorities and Regions, SALAR. 2009 http://english.skl.se/ (Accessed July 3, 2013)

20. Hanas R, John G. 2010 consensus statement on the worldwide standardization of the hemoglobin A1C measurement. Diabetes Care. 2010; 33:1903-4

21. Sjöblad S. Barn- och ungdomsdiabetes. Lund: Studentlitteratur; 2009 
22.

IDF/ISPAD guidelines. 2011 http://www.ispad.org/resource-type/idfispad-2011global-guideline-diabetes-childhood-and-adolescence (Accessed July 3, 2013)

23. Tseng CL, Brimacombe M, Xie M, Rajan M, Wang H, Kolassa J, et al. Seasonal patterns in monthly hemoglobin A1c values. Am J Epidemiol. 2005; 161:565-74

24. Craig ME, Handelsman P, Donaghue KC, Chan A, Blades B, Laina R, et al. Predictors of glycaemic control and hypoglycaemia in children and adolescents with type 1 diabetes from NSW and the ACT. Med J Aust. 2002; 177:235-8

25. Mortensen HB, Hougaard P. Comparison of metabolic control in a crosssectional study of 2,873 children and adolescents with IDDM from 18 countries. The Hvidore Study Group on Childhood Diabetes. Diabetes Care. 1997; 20:714-20

26. Nathan DM, Turgeon H, Regan S. Relationship between glycated haemoglobin levels and mean glucose levels over time. Diabetologia. 2007; 50:2239-44

27. Wilson DM, Kollman. Relationship of A1C to glucose concentrations in children with type 1 diabetes: assessments by high-frequency glucose determinations by sensors. Diabetes Care. 2008; 31:381-5

28. Nordwall M, Arnqvist HJ, Bojestig M, Ludvigsson J. Good glycemic control remains crucial in prevention of late diabetic complications--the Linkoping Diabetes Complications Study. Pediatr Diabetes. 2009; 10:168-76

29. Olsen BS, Sjolie AK, Hougaard P, Johannesen J, Marinelli K, Jacobsen BB, et al. The significance of the prepubertal diabetes duration for the development of retinopathy and nephropathy in patients with type 1 diabetes. J Diabetes Complications. 2004; 18:160-4 30. Zhang L, Krzentowski G, Albert A, Lefebvre PJ. Risk of developing retinopathy in Diabetes Control and Complications Trial type 1 diabetic patients with good or poor metabolic control. Diabetes Care. 2001; 24:1275-9 


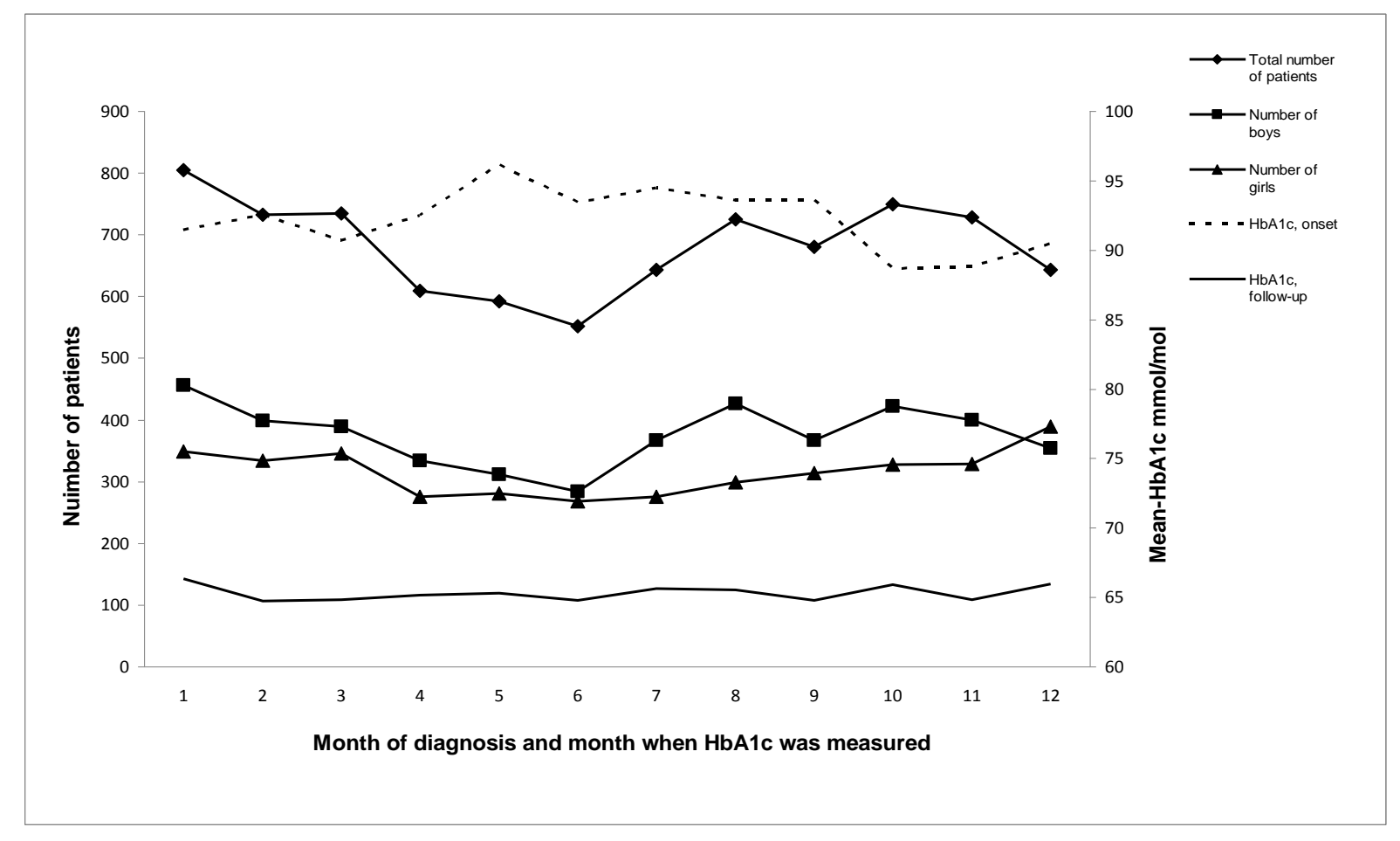

Figure 1. Monthly variation in number of children diagnosed with diabetes each month, showing the mean HbA1c (mmol/mol) for each month of diagnosis and for each month during the follow-up years 2008 to 2010.58 $\mathrm{mmol} / \mathrm{mol}$ (IFFC) corresponds to $7.5 \%$ (NGPS/DCCT) and $10 \mathrm{mmol} / \mathrm{mol}$ is about $0.9 \%$. 


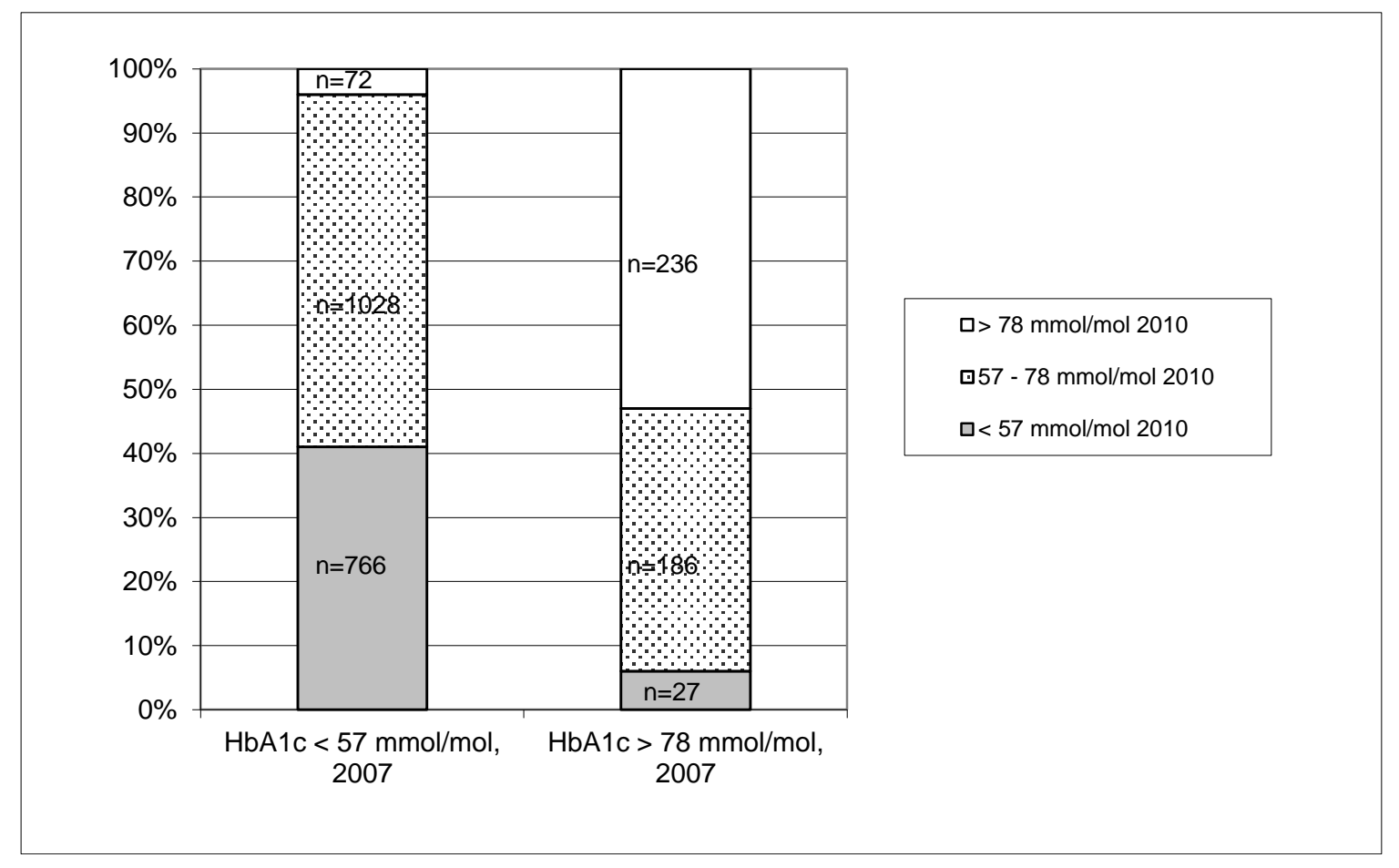

Figure 2. Proportion of patients in different HbA1c level categories in 2007 and $2010.58 \mathrm{mmol} / \mathrm{mol}$ and 78 $\mathrm{mmol} / \mathrm{mol}$ (IFFC) correspond to $7.5 \%$ and $9.3 \%$ (NGPS/DCCT), respectively. 
Table 1. HbA1c mean values $(\mathrm{mmol} / \mathrm{mol})$ at onset in boys and girls in the whole population and in different age groups by gender. $58 \mathrm{mmol} / \mathrm{mol}$ (IFFC) corresponds to $7.5 \%$ (NGPS/DCCT). P value refers to the difference between boys and girls.

\begin{tabular}{|c|c|c|c|c|}
\hline & $\mathrm{n}$ & $\begin{array}{c}\mathrm{HbA} 1 \mathrm{c} \\
\% \\
\pm \mathrm{SD} \\
\end{array}$ & $\begin{array}{c}\mathrm{HbA} 1 \mathrm{c}, \\
\mathrm{mmol} / \mathrm{mol} \\
\pm \mathrm{SD}\end{array}$ & $\mathrm{p}$-value \\
\hline \multicolumn{5}{|l|}{ Total } \\
\hline Boys & 4153 & $9.7 \pm 2.3$ & $91 \pm 24$ & $<0.001$ \\
\hline Girls & 3385 & $10.1 \pm 2.5$ & $95 \pm 27$ & \\
\hline \multicolumn{5}{|c|}{$\begin{array}{l}0 \text { to } 4 \text {-years-of-age at } \\
\text { onset }\end{array}$} \\
\hline Boys & 653 & $8.3 \pm 1.7$ & $76 \pm 18$ & $<0.001$ \\
\hline Girls & 524 & $8.6 \pm 1.7$ & $79 \pm 17$ & \\
\hline \multicolumn{5}{|c|}{$\begin{array}{l}5 \text { to } 9 \text {-years-of-age at } \\
\text { onset }\end{array}$} \\
\hline Boys & 1189 & $9.1 \pm 1.9$ & $85 \pm 20$ & $<0.001$ \\
\hline Girls & 1158 & $9.7 \pm 2.2$ & $91 \pm 23$ & \\
\hline \multicolumn{5}{|c|}{$\begin{array}{l}10 \text { to14-years-of-age at } \\
\text { onset }\end{array}$} \\
\hline Boys & 1576 & $10.3 \pm 2.3$ & $97 \pm 24$ & $<0.001$ \\
\hline Girls & 1291 & $10.9 \pm 2.7$ & $103 \pm 29$ & \\
\hline \multicolumn{5}{|c|}{$\begin{array}{l}15 \text { to } 18 \text {-years-of-age at } \\
\text { onset }\end{array}$} \\
\hline Boys & 734 & $10.6 \pm 2.5$ & $100 \pm 26$ & 0.82 \\
\hline Girls & 412 & $10.6 \pm 2.9$ & $100 \pm 30$ & \\
\hline
\end{tabular}


Table 2. Mean HbA1c mmol/mol in boys and girls at follow up in $2010.58 \mathrm{mmol} / \mathrm{mol}$ (IFFC) corresponds to $7.5 \%$ (NGPS/DCCT). P value refers to the difference between boys and girls.

\begin{tabular}{|c|c|c|c|c|}
\hline & $\mathrm{n}$ & $\begin{array}{c}\text { HbAlc, } \\
\% \\
\pm \mathrm{SD}\end{array}$ & $\begin{array}{c}\text { HbAlc, } \\
\mathrm{mmol} / \mathrm{mol} \\
\pm \mathrm{SD}\end{array}$ & p-value \\
\hline \multicolumn{5}{|c|}{$\begin{array}{l}0 \text { to } 4 \text {-years-of-age in } \\
2010\end{array}$} \\
\hline Boys & 165 & $7.3 \pm 0.9$ & $56 \pm 10$ & 0.33 \\
\hline Girls & 166 & $7.4 \pm 0.7$ & $57 \pm 8$ & \\
\hline \multicolumn{5}{|c|}{$\begin{array}{l}5 \text { to } 9 \text {-years-of-age in } \\
2010\end{array}$} \\
\hline Boys & 731 & $7.5 \pm 0.8$ & $58 \pm 9$ & 0.72 \\
\hline Girls & 584 & $7.5 \pm 0.76$ & $58 \pm 8$ & \\
\hline \multicolumn{5}{|c|}{$\begin{array}{l}10 \text { to } 14 \text {-years-of-age in } \\
2010\end{array}$} \\
\hline Boys & 1318 & $7.9 \pm 1.1$ & $62 \pm 12$ & 0.01 \\
\hline Girls & 1218 & $8.0 \pm 1.1$ & $64 \pm 12$ & \\
\hline \multicolumn{5}{|c|}{$\begin{array}{l}15 \text { to } 18 \text {-years-of-age in } \\
2010\end{array}$} \\
\hline Boys & 1714 & $8.1 \pm 1.4$ & $65 \pm 15$ & $<0.001$ \\
\hline Girls & 1417 & $8.4 \pm 1.4$ & $68 \pm 15$ & \\
\hline
\end{tabular}

